\title{
Path-Tracking Errors for Active Trailer Steering Off-Highway: A Simulation Study
}

\begin{abstract}
This paper discusses the tracking performance of a path-following steering system when operating off-highway. Simulation studies were conducted on three types of vehicle models: tractor-semitrailer, B-double and A-triple. The vehicles were simulated for a straight-line and a 450 roundabout with various road camber, grade and adhesions. Results indicated that the path-following steering system was unable to provide good tracking performance under those conditions due to longitudinal and lateral wheel slip interfering with its estimation of trailer location and orientation.
\end{abstract}

Keywords: simulation study, path-following control, active steering, off-highway

\section{Introduction}

Active trailer steering systems can significantly improve the low speed manoeuvrability of articulated vehicles. Previous studies were carried out on level road surfaces with relatively high levels of tyre-road adhesion. In this paper a path-following trailer steering system is simulated for low adhesion, non-level, 'off-highway' conditions. These off-highway conditions are typically seen in heavy vehicle applications such as: milk/livestock collections from farms, and transportation of raw materials for primary industries such as logging and sugarcane and military supply.

The application of high accuracy path-following trailer steering in these transport operations would relax the low-speed manoeuvrability constraints that limit the capacity of the existing vehicles [1]. It could enable use of tractor-semitrailer vehicles instead of short rigid lorries for some farm collections, and use of multiple-unit articulated vehicles instead of tractor-semitrailers for logging, sugarcane and military supply.

By using higher capacity vehicles in these operations, fuel consumption (greenhouse gas emissions) and shipping costs could be reduced significantly. In Canada, shipping costs were reduced by $30 \%$ when long combination vehicles were introduced in the 1980s [2]. For transport of military supplies, fewer trips and fewer drivers would also ensure less exposure to military threat, improving the safety of the supply line.

Existing electronic path-following trailer-steering systems [3, 4] are able to improve low-speed manoeuvrability of articulated vehicles. These improvements can enable multiply-articulated long combination vehicles to satisfy the legal requirements for manoeuvrability on UK roads [5]. However these steering systems are not designed to operate off-highway, where wheel slip can cause measurement errors and the resulting incorrect steering actuator demand signals can cause the trailer wheels to deviate significantly from the correct path.

To investigate the effects of adverse road conditions on the path-following performance of active steering controllers, a parametric study is performed in this paper. The performance of articulated vehicles with electronic trailer steering is simulated for roads with significant camber, longitudinal grade and low tyre-road adhesion.

This study is a precursor to the development of active steering systems that can operate off-highway. The aim is to understand the road surface conditions where the path-following performance of active steering systems degrades, thereby indicating directions for possible solutions.

\section{Path-following control strategy}

The first low-speed path-following trailer steering control algorithm was proposed by Jujnovich [4], working under the umbrella of the Cambridge Vehicle Dynamics Consortium (CVDC). This was a nonlinear controller which set the heading angle of a 'follow-point' on the trailer to be the same as that of a 'lead point' on the tractor at the corresponding location along the path (Figure 1 (a)). A reference trailer model was used to handle situations in which the steer angles of the trailer wheels saturated due to limits on wheel clearance. Cheng [3] devised an alternative approach to the same control problem by minimizing the path-tracking error using a linear controller, without the need for a reference trailer (see Figure 1 (b)).

A block diagram of Cheng's low-speed control algorithm is shown in Figure 2. Measurements of tractor longitudinal speed, $\mathrm{u}_{1}$, tractor front wheel steer angle, $\delta_{1 \mathrm{f}}$, trailer yaw rate, $\dot{\psi}_{2}$, and articulation angle, $\Gamma$, are fed into a linear yaw-plane model of the tractor-semitrailer, with the assumption of zero tyre sideslip for all wheels 
(i.e. the semi-trailer axle wheels are steered in the direction of their travel). This model is used to calculate the positions of the lead point (the tractor 5th wheel) and follow point (the trailer rear end) in the global coordinate system and hence to steer the trailer wheels to minimise the path-tracking error.

In this paper, Cheng's model is extended to vehicle combinations with multiple trailers or dollies. It can, therefore, calculate the motion of long combination vehicles (LCVs) such as a B-double or A-triple. The corresponding lead and follow points for articulated vehicles are given below:

- $\quad$ For tractor/semitrailer, the mid-point of the rear doors on the trailer is chosen as the follow point. It follows the path of the $5^{\text {th }}$ wheel of the tractor unit.

- $\quad$ For the B-double combination, the tractor $5^{\text {th }}$ wheel is the first lead point. The first follow point is the rear hitch of the B-trailer, which also acts as the second lead point. The mid-point of the rear doors on the A-trailer is the second follow point.

- $\quad$ For the A-triple combination, the tractor $5^{\text {th }}$ wheel is the first lead point followed by the rear end of the first trailer. The $5^{\text {th }}$ wheel on the first dolly follows its towing point on the first trailer and the rear of the second trailer follows its $5^{\text {th }}$ wheel. The same applies to the second dolly and the third trailer.

Following Jujnovich's approach [1], with the notation in Figure 3, the sideslip, heading and position of the 5th wheel on the tractor can be calculated by assuming that the wheels on the tractor drive axle do not sideslip at low speeds:

$$
\begin{gathered}
\beta_{1}^{5 \mathrm{w}}=\tan ^{-1}\left(\frac{\mathrm{b}}{\mathrm{c}} \tan \left(\delta_{1 \mathrm{f}}\right)\right) \\
\beta_{2}^{5 \mathrm{w}}=\beta_{1}^{5 \mathrm{w}}-\Gamma \\
\gamma_{5 \mathrm{w}}=\psi_{1}+\beta_{1}^{5 \mathrm{w}} \\
\mathrm{X}_{5 \mathrm{w}}=\int \frac{\mathrm{u}_{1}}{\cos \left(\beta_{1}^{5 \mathrm{w}}\right)} \cos \left(\gamma_{5 \mathrm{w}}\right) \mathrm{dt} \\
\mathrm{Y}_{5 \mathrm{w}}=\int \frac{\mathrm{u}_{1}}{\cos \left(\beta_{1}^{5 \mathrm{w}}\right)} \sin \left(\gamma_{5 \mathrm{w}}\right) \mathrm{dt}
\end{gathered}
$$

Where: $\quad \mathrm{X}_{5 \mathrm{w}}=\mathrm{x}$ position of $5^{\text {th }}$ wheel in global coordinates $[\mathrm{m}]$

$\mathrm{Y}_{5 \mathrm{w}}=\mathrm{y}$ position of $5^{\text {th }}$ wheel in global coordinates $[\mathrm{m}]$

$\gamma_{5 \mathrm{w}}=$ heading angle of $5^{\text {th }}$ wheel $[\mathrm{rad}]$

$\mathrm{u}_{1}=$ longitudinal speed of tractor unit $[\mathrm{m} / \mathrm{s}]$

$\beta_{1}^{5 \mathrm{w}}=$ sideslip angle of $5^{\text {th }}$ wheel in tractor coordinates

$\beta_{2}^{5 \mathrm{w}}=$ sideslip angle of $5^{\text {th }}$ wheel in trailer coordinates [rad]

$\Gamma=$ articulation angle $[\mathrm{rad}]$

$\delta_{\mathrm{f}}=$ tractor front steer angle $[\mathrm{rad}]$

b, $c=$ distance shown in Figure 3 (a)

The distance travelled down the path by the 5 th wheel of the tractor can be found from:

$$
\mathrm{S}_{5 \mathrm{w}}=\int \frac{\mathrm{u}_{1}}{\cos \left(\beta_{1}^{5 \mathrm{w}}\right)} \mathrm{dt}
$$

The motion of the follow point on the semi-trailer unit is given below as an example. Similar equations can be written to determine the follow points of the other vehicle units (shown in Figure 3).

$$
\begin{gathered}
X_{r}=X_{5 w}-1 \cos \psi_{2} \\
Y_{r}=Y_{5 w}-1 \sin \psi_{2}
\end{gathered}
$$

Where: $\quad \mathrm{Xr}=$ longitudinal position of follow point in global coordinates $[\mathrm{m}]$

$\mathrm{Yr}=$ lateral position of follow point in global coordinates [m]

$\Psi_{\mathrm{i}}=$ yaw angle of vehicle unit 'i' [ $\left.\mathrm{rad}\right]$

$1=$ distance from each follow point to the its lead point, see Figure 3 [m]

The global position of the lead point is stored in a data buffer, and then transformed into a trailer-fixed coordinate system (the trailer rear end as the origin). Thus the path tracking error of each follow point with 
respect to the path of its lead point can be determined easily. The path error is then fed into a ProportionalIntegral-Derivative (PID) controller to determine the steer angle of a "virtual wheel" at the trailer rear end. Finally the steer angles of all trailer axles can be determined from the geometry of the vehicle, by assuming zero sideslip of the tyres.

If a controller with fixed time step is used, the position of the 5th wheel can be stored in a data buffer on each time step. However, when the vehicle is travelling very slowly, the data buffer would become very large. An alternative approach is to store the path of the 5 th wheel at a set number of points with fixed distance spacing along the length of the trailer [3]. The 5th wheel position at a particular time can be interpolated linearly from this array. This is the approach used here. The spacing was set to be $0.1 \mathrm{~m}$ with a buffer size of 200 in the simulation. These settings ensured that a sufficiently long path can be stored in the buffer.

This controller, which is similar to Cheng's [3], differs from Jujnovich's low speed controller [4] in two aspects. One is that Jujnovich's low speed controller was based on heading angle information while this controller is based on the path-tracking position error. This alternative approach avoids the possibility of steadystate tracking error, which can occur for Jujnovich's controller, for example, on road surfaces with significant camber. The other is that Jujnovich's low speed controller employed a model matching control technique with a 'reference' model to handle steer angle saturation. This controller employs a feedback technique to minimise the path-tracking error. When saturation occurs, the controller demands maximum steer angles and minimises the lateral tyre forces of all axles. This approach enables the vehicle to get back on track once tyre saturation stops.

\section{Vehicle model}

Three different vehicle combinations were simulated in this parametric study (see Fig.3(c)): a tractor-semitrailer, a B-double and an A-triple. The reasons for simulating these three types of articulated vehicles and the structure of each vehicle combination are introduced below:

- The tractor-semitrailer is the most common heavy goods vehicle. The configuration simulated is typical of UK vehicles with $38 \mathrm{t}$ gross vehicle weight (GVW). It consists of a tractor coupled to a three-axle semi-trailer (A-trailer) by a $5^{\text {th }}$ wheel at the front end of the trailer.

- The B-Double combination is very widely employed in road transport used in Australia, New Zealand, Canada, Argentina and South Africa. It consists of a tractor and two trailers: a two or three-axle 'link' trailer (B-trailer) and an A-trailer. The B-trailer links the tractor to the A-trailer. It has $5^{\text {th }}$ wheels at both the front and rear; while the A-trailer, has a $5^{\text {th }}$ wheel at the front.

- The A-Triple combination is the longest vehicle combination commonly used in road transport, for example, in rural areas in Australia and some parts of the USA. It combines six vehicle units, i.e. a tractor unit, two dollies and three A-trailers. Each of the dollies has two or three axles and is linked to the rear of the A-trailer in front with a pintle hitch.

\section{Overall model structure}

Non-linear yaw/roll articulated vehicle models were developed for the study. They captured the low-speed straight line and cornering behaviour. The models consisted of 5 sub-models that interact with each other. For a given manoeuvre, the drive torque and steer angle of the tractor unit are determined by the driver model. The trailer steer angles were derived from the trailer steering control laws. In addition to the steer angles, the vertical load on each tyre was also required to calculate the tyre force. The tyre forces were then fed into the vehicle dynamics model, completing the loop. Each sub-model is summarized below.

\section{Vehicle dynamics Sub-model}

The vehicle dynamics sub-model had longitudinal, lateral, roll and yaw degrees of freedom for both the tractor and the trailer(s) as shown in Fig. 3. The equations of motion for the tractor and trailers were developed separately and connected together by the kinematic constraints and force balance equations at each hitch point. This is a general approach that can model vehicle combinations with multiple units with arbitrary numbers of trailers and dollies.

Application of Newton's Second Law yielded four differential equations for the tractor unit (lateral and longitudinal forces; roll and yaw moments) and four differential equations for each of the trailer units. Another four equations were determined according to compatibility of velocities and force balance at each coupling as shown in Fig. 4. Details of the vehicle models including the equations of motion and parameter values can be found in [6]. 


\section{Driver sub-model}

The driver sub-model controlled the tractor steering and speed. The task of the lateral driver model was to ensure that the front of tractor unit followed the desired path. This was achieved by proportional control using a single preview point input. The longitudinal driver model maintained constant speed when additional traction torque was needed, for instance, uphill or along a slippery road. A proportional controller was implemented to achieve the desired vehicle speed by applying an appropriate driving torque on tractor driven axle.

\section{Trailer steering sub-model}

The trailer steering sub-model determines the steer angle of each trailer axle using the steering control algorithm. The limits on the steer angle of each trailer axle depend on the suspension geometry and chassis width. The steer angle of each axle in the tri-axle trailer group was limited to $16.7^{\circ}, 16.7^{\circ}$ and $23.5^{\circ}$ respectively, as per the CVDC's experimental actively-steered semitrailer [7]. The limiting steer angles of the B-link trailer and dolly were both $33.5^{\circ}$.

\section{Vertical load sub-model}

The vertical load on each tyre has a static component (determined from static masses and dimensions) plus lateral load transfer due to roll and lateral acceleration of the sprung mass. These variations in vertical tyre force strongly affect the adhesion available from the tyres and the lateral force-generating characteristics of the tyres.

Steady-state road camber and longitudinal grade can introduce additional forces in the lateral and longitudinal directions, proportional to the weight of the vehicle unit. The lateral force caused by vehicle weight also produces a roll moment around the roll axis of each vehicle unit. All these effects were considered by the vehicle dynamics model developed here.

The lateral load transfer determined the vertical load transferred to each wheel due to roll motion of the sprung mass. These variations in vertical tyre force strongly affect the adhesion available from the tyres and their lateral force-generating characteristics.

\section{Tyre force sub-model}

For the tyres on non-driving axles, i.e. the front axle of tractor unit and all trailer axles, the tyre force sub-model was used to determine the lateral force generated by each tyre. The semi-empirical 'brush' tyre model proposed by Fancher et al. [7] was used, with parameters suitable for truck tyres [1].

For the tyres on the tractor driving axle, additional traction torque is required for operations on the slippery surface or uphill with longitudinal tyre force generated at the same time. A combined tyre model [8] was, therefore adopted for the tractor drive axle. The nominal coefficient of friction in the tyre model is varied to simulate different adhesion conditions.

\section{Performance measures}

Among the possible performance measures for low-speed manoeuvres, the path-tracking error (off-tracking) at the follow point (the rear end) relative to the lead point of each vehicle unit was of most interest in this study. Two other factors that have an important influence on the controller: sideslip at the 5th wheel and forward speed measurement errors, were also considered.

\section{Model validation}

To validate the vehicle model and the steering algorithm, simulation results for a roundabout manoeuvre on a high-friction flat road were compared with field test results for the same manoeuvre of the CVDC test vehicle [3], with both steered and non-steered trailers (Figure 5). The agreement between simulation and experiment is seen to be good for both the unsteerd and steered cases.

Whereas the experimental data for the non-steered trailer shows a path-tracking error of $2.6 \mathrm{~m}$ in this manoeuvre, the error for the steered trailer is less than $0.2 \mathrm{~m}$, which is approximately half the width of a tyre.

The steady lateral off-tracking error of the path-following controller mainly arises from the assumption in the control algorithm that the sideslip of tyres on tractor axles is zero. This assumption is accurate at very low speeds but becomes less accurate as vehicle speed increases. 


\section{Parametric study}

The effects of various road conditions on vehicle tracking errors for a $450^{\circ}$ 'standard UK roundabout' [1] and a straight-line path at low speeds were investigated (Figure 6). Simulations were performed with various levels of road camber, road grade and tyre-road adhesion for the three vehicle configurations.

\section{Path-tracking performance for path-following steering on tractor-semitrailer: $450^{\circ}$ roundabout}

The steady-state path-tracking errors of the follow point (trailer rear end) relative to the path of the lead point (tractor 5th wheel) for the tractor-semitrailer are summarized in Table 1.

In tests 1-8, the effects of each parameter on the path-following errors were investigated individually. Then, the path-following performance was simulated for simultaneous changes of multiple parameters in tests 9-11. The path-following controller assumes the sideslip angle at the tractor drive axle is $0^{\circ}$ at low speeds. This assumption enables the sideslip at the 5th wheel to be estimated by the equation below and used in the controller:

$$
\mathrm{v}_{5 \text { th-wheel }}=\frac{\mathrm{u}_{1}}{\cos \left(\beta_{1}^{5 \mathrm{w}}\right)}
$$

Absolute velocity at the 5th wheel of the tractor is another important measurement input to the active steering controller. These two measurements can have significant influence on the performance of the steering controller and thus were also investigated by the simulations.

\section{Effect of vehicle speed}

In tests $1-3$, the effect of vehicle speed on the path-following performance of the path-error controller is investigated. The vehicle model was simulated negotiating the roundabout on a flat surface (no camber or grade) with high tyre-road adhesion (0.8) at the speed of $5 \mathrm{~km} / \mathrm{h}, 10 \mathrm{~km} / \mathrm{h}$ and $15 \mathrm{~km} / \mathrm{h}$. The corresponding steady-state path-tracking error increases from $30 \mathrm{~mm}$ at $5 \mathrm{~km} / \mathrm{h}$ to $290 \mathrm{~mm}$ at $15 \mathrm{~km} / \mathrm{h}$ (see Figure 7 (a)). This is because the sideslip estimation at the tractor 5th wheel using eq. 9 becomes less accurate as vehicle speed increases.

Figure 7 (b) presents the sideslip at the tractor 5th wheel for tests 1-3. In this figure, the 'estimated value' of the sideslip at the 5th wheel is calculated using eq. 9 while the 'real value' is the output from the vehicle model. From the figure, it can be seen that the steady-state error between the 'estimated value' and the 'real value' increases from $0.2^{\circ}$ at $5 \mathrm{~km} / \mathrm{h}$ to $1.5^{\circ}$ at $15 \mathrm{~km} / \mathrm{h}$. This is due to the lateral force applied at the 5 th wheel by the trailer. This force arises from the combination of the net yaw moment on the trailer axle group due to tyre scrub and the centrifugal force on the trailer as the speed increases. The net yaw moment on the trailer axle group is small for the actively-steered case, since the side forces are deliberately controlled to be as small as possible [72]. However, the centrifugal force increases significantly for higher speeds. The sideslip estimation and the consequent path-following performance therefore degrade when vehicle speed increases.

\section{Effect of road camber}

The effect of road camber on path-tracking error was investigated in tests 1, 4 and 5. The vehicle speed was set as $10 \mathrm{~km} / \mathrm{h}$ and the tyre-road friction coefficient was set to be 0.8 in these tests. Only the road camber angle varied from $-5^{\circ}$ to $5^{\circ}$ in this group of tests. The results show that an inward road camber can reduce the steady state tail-swing while an outward road camber increases the tail-swing. However, road camber can also introduce a constant path-tracking error for the straight-line parts of simulation before and after the circular parts of the manoeuvre (see Figure 8 (a)). From the table, a $\pm 5^{\circ}$ road camber will cause an extra $-160 \mathrm{~mm} /+190 \mathrm{~mm}$ path-tracking error relative to the baseline (test 1), the sign of which depends on the direction of road camber. This is primarily caused by the additional sideslip at the 5th wheel due to the road camber.

Figure 8 (b) shows the sideslip at the tractor 5 th wheel for tests 1,4 and 5 . From the figure, a $5^{\circ}$ road camber introduces $0.7^{\circ}$ difference in steady-state sideslip at the vehicle speed of $10 \mathrm{~km} / \mathrm{h}$. An inward camber reduces the error of sideslip estimation (the error between the 'estimated value' and the 'real value') while outward camber increases it. This is because road camber causes a lateral force proportional to vehicle weight, which makes the trailer sideslip in the direction of the camber and, in-turn, applies a lateral force to the 5 th wheel. Hence, for a cornering manoeuvre, an inward camber angle causes additional 'cut-in' at the 5th wheel while an outward camber angle reduces cut-in.

\section{Effect of tyre-road adhesion}

The effect of tyre-road adhesion on the path-tracking performance was simulated in tests 1 and 6 . The vehicle speed was set to be $10 \mathrm{~km} / \mathrm{h}$ and no road camber or grade was introduced in the simulation. The path-tracking error slightly degraded from $130 \mathrm{~mm}$ in test 1 to $180 \mathrm{~mm}$ in test 6 , when the nominal road friction coefficient was reduced from 0.8 to 0.1 (see Figure 9 (a)). For the same sideslip angle at each axle, the corresponding lateral 
tyre force decreases if the friction coefficient is lower. The trailer unit slips outwards to gain a new equilibrium, resulting in a larger tail-swing.

The accuracy of the sideslip estimation decreases under lower adhesion conditions. Figure 9 (b) shows the effect of varying tyre-road adhesion on the sideslip at the 5th wheel. For actively steered trailers, the effect of low tyre-road friction on the sideslip estimation is considerably reduced, due to substantial reduction of lateral forces on the trailer axles and hence yaw moment on the axle group (see also [1]). From the figure, the sideslip error increases from $0.6^{\circ}$ to $0.8^{\circ}$ when road friction drops from 0.4 to 0.1 . Hence, the path-following steering controller can still present adequate tracking performance (within $200 \mathrm{~mm}$ ) under low-friction road conditions at low speeds.

\section{Effect of road grade}

The effect of road grade was investigated by simulating an uphill 'spiral roundabout' on a high friction surfaces in tests 1,7 and 8. This is not a realistic manoeuvre though a segment of the manoeuvre might be representative of an uphill corner on a mountain road. The vehicle travelled at $10 \mathrm{~km} / \mathrm{h}$ and the road grade angle was $5^{\circ}$ in the simulation.

Longitudinal wheel slip can occur on the tractor drive axle for operations on the slippery surfaces and particularly, when travelling uphill. A corresponding error will therefore be included in any vehicle speed measurement that uses a wheel speed sensor on the tractor drive axle. Non-driven trailer axles do not suffer from speed errors due to drive torque, but will suffer speed measurement errors in down-hill manoeuvres under braking, though generally to a lesser extent. By u sing wheel speed sensors on different axles, i.e. tractor drive axle or trailer axles, estimates of vehicle velocity at the 5th wheel can differ. In addition to the method in eq. 9 , vehicle velocity at 5 th wheel can also be estimated using the signal from trailer front axle, $\mathrm{u} 2$ :

$$
\mathrm{v}_{5 \text { th-wheel }}=\frac{\mathrm{u}_{2}}{\cos \left(\beta_{2}^{5 \mathrm{w}}\right)}
$$

Assuming the sideslip angle at $5^{\text {th }}$ wheel was known accurately, the errors of vehicle speed measured by these two approaches (i.e. on the tractor drive or trailer wheels) were investigated.

Results in Table 1 show a tail-swing of $260 \mathrm{~mm}$ when measuring wheel speed from the tractor drive axle (test 7). This is primarily due to the errors in both vehicle heading and forward speed measurement. Using the wheel speed measurement from the trailer front axle, this error becomes a cut-in of $180 \mathrm{~mm}$ (test 8), which is mainly caused by improper sideslip estimation at the 5th wheel by eq. 1 (see Figure 10 (a)).

Figure 10 (b) shows the estimated forward speed (by eq. 2 and 3) with comparison of its 'real value' (output from the vehicle model) when road grade is $5^{\circ}$. Errors in the estimation of sideslip at the 5 th wheel were assumed to be removed in this simulation. From the figure, the vehicle speed measured from the tractor wheel speed sensor has an error of $0.6 \mathrm{~km} / \mathrm{h}$ compared to its true value. Replacing the tractor wheel speed signal with that from the trailer, the vehicle speed measurement error is reduced to a low level of about $0.01 \mathrm{~km} / \mathrm{h}$.

However, using the trailer wheel speed measurement can only eliminate the error caused by longitudinal slip at the tractor drive axle. The combination of road grade and articulation angle can introduce lateral forces and errors in sideslip at the 5th wheel in a similar way to road camber. Furthermore, the heading angle of the trailer axles leads to cosine errors in longitudinal velocity, which are integrated when determining the position of the 5 th wheel, resulting in inaccurate vehicle position estimates (see Figure 10 (c)).

\section{Effect of changing two parameters simultaneously}

When changing two parameters at a time, the path-tracking performance can become considerably worse. This is investigated in tests $1,9,10$ and 11 .

The effects of simultaneously introducing a $5^{\circ}$ road camber and a $5^{\circ}$ road grade are simulated in test 1 and 9 . The vehicle travelled at $10 \mathrm{~km} / \mathrm{h}$ on high-friction roads in the simulation. Compared to the baseline pathtracking error of $130 \mathrm{~mm}$ on a flat ground, the error increases substantially to $500 \mathrm{~mm}$ for this scenario (see Figure 11 (a)). This is due to the combined errors in both vehicle speed and heading measurement at the 5 th wheel, which lead to less accurate path data acquisition and steering control than either of the errors alone.

The effect of simultaneously varying road camber and tyre-road adhesion is investigated in tests 1,10 and 11 . The vehicle model was simulated to travel at $10 \mathrm{~km} / \mathrm{h}$ on low-friction roads with $\pm 5^{\circ}$ road cambers. Pathtracking error on the low friction surface remained the same as the high friction surface for an inward road camber; while the path-tracking error increased considerably to 600mm for outward camber (see Figure 11 (b)). The outward camber acted in the same direction as the centrifugal force while the inward camber opposed it. In addition, the effective tyre cornering stiffness decreases as tyre-road adhesion gets lower. As a result, wheels are much more likely to slip outwards due to adverse camber, particularly on low friction roads. 
Path-tracking performance for path-following steering on longer combination vehicles: straight-line with camber

Road camber, road grade, higher vehicle speed and low tyre-road adhesion can introduce errors in estimated vehicle heading and forward speed at the tractor 5th wheel. This leads to an integrated error in vehicle position data and therefore a consequent error in demanded trailer steer angles. Compared to the tractor-semitrailer, the rear ends of longer combination vehicles would further deviate from the path of the front due to the additional articulation joints, greater vehicle length and mass.

Actively steered B-double and A-triple vehicles were simulated for a straight line manoeuvre with variations in road cambers and tyre-road adhesion. The vehicle speed was set to $10 \mathrm{~km} / \mathrm{h}$ in these tests. The path-tracking errors at the rear end of vehicle combinations relative to the tractor front end for each test are provided in Table 2.

In tests 12 and 13, the B-double and A-triple vehicles were simulated for a straight line manoeuvre on a flat, high friction surface $(\mu=0.8)$, to provide baseline performance. As expected, 'perfect' path-following was achieved since there were no errors in sideslip or velocity estimation for this simple manoeuvre.

In tests 14 and 15, Table 2, the path-tracking errors were calculated for the B-double and A-triple vehicles for a straight line manoeuvre on a cambered, high friction surface $(\mu=0.8)$. The road camber was set to be $5^{\circ}$ in the tests. A large sideslip error at the 5 th wheel of the tractor and also the resultant error in vehicle position data lead to a significant overall path-tracking error of 330mm at the rear end of B-double combination. Figure 12 (a) shows that this error builds up gradually with distance travelled and then levels off to a steady state value. For the A-triple combination, a larger off-tracking error of $560 \mathrm{~mm}$ at the rear end of the vehicle combination is caused by the $5^{\circ}$ road camber (see Figure 12 (b)). The overall path-tracking error increases as the total length of the vehicle combination increases for the straight line manoeuvre on a cambered surface. Path-tracking errors of this magnitude in a straight line would likely be unacceptable.

In tests 16 and 17, the straight line manoeuvre was simulated on a cambered, low friction surface. The road camber was set to be $5^{\circ}$ and the coefficient of friction, $\mu$, was set to 0.1 in the tests. Overall path-following performance was further degraded for the B-double and A-triple vehicles, showing around $0.9 \mathrm{~m}$ and $1.2 \mathrm{~m}$ offtracking at the rear ends of each vehicle respectively (see Figure 13). Low adhesion can lead to significant longitudinal wheel slip for wheels on the drive axle and also reduce effective tyre cornering stiffness for all wheels. Consequently, path-following performance degrades for these conditions.

Path-tracking performance for path-following steering on longer combination vehicles: $450^{\circ}$ roundabout

Simulations for the $450^{\circ}$ roundabout manoeuvre were performed for the B-double and A-triple vehicles. Vehicle speed was set to be $10 \mathrm{~km} / \mathrm{h}$ in these tests. Other parameters, such as road camber, grade and adhesion, were varied to investigate their effects on the path following errors. The path-tracking errors at the rear end of vehicle combinations relative to the tractor front end for each test are provided in Table 3.

In tests 18 and 19, the B-double and A-triple vehicles were simulated for the $450^{\circ}$ roundabout on a flat surface, which created the baselines for this manoeuvre. Road friction coefficient was set to be 0.8 in the tests. An overall path-tracking error of $1.02 \mathrm{~m}$ occurred at the rear end of the B-double. This is expected [1] because the tractor 5th wheel cuts in by $1.01 \mathrm{~m}$ on the roundabout. The path-tracking errors between either pair of lead and follow points were $-120 \mathrm{~mm}$ and $10 \mathrm{~mm}$ (see Figure 14 (a)). For the A-triple vehicle, the path-following performance was presented in Figure 14 (b). Steady-state off-tracking errors at rear ends of each trailer were within the range between $1.02 \mathrm{~m}$ and $1.25 \mathrm{~m}$.

Only the first trailer of each vehicle combination performed as expected from test 1 . The other trailer units behave differently. This is primarily because the forces and the errors of estimated sideslip at each hitch point differ. The difference between the first and the last articulation joints could be significant since the first trailer did not perform perfect path-following.

The effect of low tyre-road adhesion on overall path-tracking error was simulated in tests 20 and 21 . Road friction coefficient was set to be 0.1 in the tests. It was found in earlier simulations that low adhesion can introduce an additional tail-swing to the path-tracking errors. For the B-double, an overall path-tracking error of $0.92 \mathrm{~m}$ at the rear end of the vehicle combination (see Figure 15 (a)). That is an additional $0.1 \mathrm{~m}$ tail-swing compared to the baseline (test 18, Figure 15 (a)), which agrees with the findings of test 6 .

For the A-triple, the performance degrades considerably compared to the B-double. The steering angles of each trailer begin to saturate at the end of the roundabout manoeuvre (see Figure 15 (b)). This is primarily due to the integral errors of wheel speed caused by large longitudinal wheel-slip. Integral wind-up of the PID controller introduces excessive overshoot after the saturation and steer the trailer in the opposite direction. This causes a large lateral force on the tractor 5th wheel and therefore large lateral tyre forces. Hence, the tyres on the tractor 
drive axle cannot generate sufficient longitudinal force to maintain constant speed due to low adhesion, the tyres slip and the system fails completely.

The effect of a $\pm 5^{\circ}$ road camber on overall path-tracking error was simulated in tests $22-25$, Table 3 and Figure 16 (a-d). As discussed earlier, an inward camber can introduce a steady-state cut-in at the rear of the vehicle combination while an outward camber can introduce a steady-state tail-swing. The magnitude of this cut-in distance mainly depends on the errors in sideslip estimation at each lead point. For the B-double, a $\pm 5^{\circ}$ road camber can cause a path-tracking error of $1.32 \mathrm{~m}$ or $0.72 \mathrm{~m}$ at the rear end of the vehicle combination (see Figure 16 (a)). That is an additional $\pm 0.3 \mathrm{~m}$ off-tracking compared to the baseline (test 18, Figure 14 (a)). For the A-triple, the overall path-tracking errors, under those conditions, are around $1.22 \mathrm{~m}$ (see Figure 16 (b)). With $-5^{\circ}$ of road camber, the path-tracking errors are slightly less as expected (see Figure 16 (c) and (d)).

The path-following performance of the B-double travelling around the $450^{\circ}$ spiral roundabout is investigated in test 26 . From earlier analysis and simulation, negotiating a $450^{\circ}$ roundabout with $5^{\circ}$ road grade can introduce an extra tail-swing at the follow points of each trailer. Wheels on the drive axle would slip more for the Bdouble since a larger force, proportional to vehicle total mass, pulls the tractor backwards, causing significant errors in longitudinal position estimation and also the consequent steering demand signals. The result shows that, for this condition, the overall steady-state path-tracking error for the B-double is $-0.22 \mathrm{~m}$ at the rear end of the vehicle combination (see Figure 17 (a)). The tracking error relative to the tractor 5 th wheel (follow point) exceeds $1 \mathrm{~m}$ in the direction of tail-swing. Besides that, an entry tail-swing over $0.63 \mathrm{~m}$ is also shown in the test, which can potentially cause significant safety concerns because it occurs in the driver's blind spot and causes the rear end of the vehicle to drive out of the traffic lane.

For the A-triple, the performance is even worse. The tyres on the tractor drive axle cannot generate sufficient longitudinal forces to pull the vehicle uphill whist maintaining constant speed. From Figure 17 (b), these tyres slip excessively in the longitudinal direction, especially when the front steer angle is applied and the system fails. Hence, path-following errors are not presented for this case.

Finally, the effect of simultaneously introducing road camber and road grade on path-tracking error of the Bdouble was simulated in test 28 . The performance considerably degrades (see Figure 17 (c)), with a substantial entry tail-swing of $0.92 \mathrm{~m}$ at the rear end of the vehicle combination. The trailers did not follow the path of tractor 5th wheel, showing steady state off-tracking around $1.2 \mathrm{~m}$ (with respect to tractor 5 th wheel). The error in position data at the rear end of the 2 nd trailer caused by the combined errors in vehicle heading and forward speed measurement at the 5th wheel of the tractor unit is amplified by the longer vehicle length, leading to less steering control and worse accuracy in path following. Under this condition, the entry tail swing is around $0.92 \mathrm{~m}$, which is clearly unacceptable for any roundabout manoeuvre.

\section{Conclusions}

A tractor-semitrailer vehicle with electronically-controlled path-following trailer steering was simulated for offhighway conditions, to investigate the effects of adverse wheel-road adhesion conditions on path-tracking errors. Operation on: (a) cambered surfaces, (b) at higher vehicle speeds and (c) under conditions of reduced tyre-road adhesion all introduce significant sideslip at the $5^{\text {th }}$ wheel of the tractor unit, resulting in an integrated error in vehicle position data and a consequent error in demanded trailer steering angles.

(I) Manoeuvres on slippery surfaces or uphill introduce errors in vehicle speed measurement from the tractor drive axle, which lead to inaccurate vehicle position estimates. Using the wheel speed measurement from the trailer axles can reduce the error caused by longitudinal wheel slip but still fails to give accurate velocity at the 5 th wheel due to errors caused by the heading angle.

(II) Individual adverse factors - camber, road grade, low friction - typically result in less than 300mm of path-tracking error at the follow point (rear end of the trailer) for the tractor-semitrailer.

(III) Combinations of adverse factors, such as low adhesion on a cambered corner, can cause up to $600 \mathrm{~mm}$ of path-tracking error at the follow-point of the tractor-semitrailer.

(IV) Adoption of path-following trailer steering systems on longer combination vehicles causes significant overall path-tracking errors at the rear end of vehicle combination, for various levels of road camber and adhesion. For straight line tests on a cambered surface, the rear ends of the B-double and A-triple vehicles were found to slip laterally by $330 \mathrm{~mm}$ and $560 \mathrm{~mm}$ respectively relative to the front end of each vehicle combination. On a slippery surface, the performance was even worse, showing the offtracking of $910 \mathrm{~mm}$ and $1190 \mathrm{~mm}$ at the rear ends of the vehicle combinations.

(V) For the $450^{\circ}$ roundabout, the effects of those parameters on path-tracking performance primarily agree with previous findings of tractor-semitrailer. The combination of road camber and road grade can cause up to $1 \mathrm{~m}$ entry tail-swing at the rear end of B-double. This is approximately half a lane width, which is not acceptable. The A-triple runs out of drive traction on this manoeuvre. This, combined with 
saturation of the trailer steer angles causes the system to fail completely.

Tables

\begin{tabular}{ccccccc}
\hline Test & $\begin{array}{c}\text { Road } \\
\text { camber } \\
{[\text { degree] }}\end{array}$ & $\begin{array}{c}\text { Friction } \\
\text { coefficient } \\
{[-]}\end{array}$ & $\begin{array}{c}\text { Road } \\
\text { grade } \\
{[\text { degree }]}\end{array}$ & $\begin{array}{c}\text { Vehicle } \\
\text { speed } \\
{[\mathrm{km} / \mathrm{h}]}\end{array}$ & $\begin{array}{c}\text { Steady-state } \\
\text { tracking error* } \\
{[\mathrm{mm}]}\end{array}$ & $\begin{array}{c}\text { Parameter } \\
\text { changes }\end{array}$ \\
\hline 1 & 0 & 0.8 & 0 & 10 & -130 & Baseline \\
\hline 2 & 0 & 0.8 & 0 & 5 & -30 & Vehicle speed \\
3 & 0 & 0.8 & 0 & 15 & -290 & Road camber \\
\hline 4 & 5 & 0.8 & 0 & 10 & 60 & -290 \\
\hline 5 & -5 & 0.8 & 0 & 10 & -180 & Adhesion \\
\hline 6 & 0 & 0.1 & 0 & 10 & -260 (tractor) & Road grade \\
\hline 8 & 0 & 0.8 & 5 & 10 & 180 (trailer) & -500 \\
\hline 10 & 0 & 0.8 & 5 & 10 & 60 & Grade \& camber \\
\hline 11 & -5 & 0.8 & 5 & 10 & Adhesion \\
\hline
\end{tabular}

Table 1: Path-following performance for tractor-semitrailer: $450^{\circ}$ roundabout.

$*$ calculated at the rear doors of the semi-trailer with respect to the $5^{\text {th }}$ wheel

\begin{tabular}{ccccccc}
\hline Test & $\begin{array}{c}\text { Vehicle } \\
\text { type } \\
{[-]}\end{array}$ & $\begin{array}{c}\text { Road } \\
\text { camber } \\
{[\text { degree] }}\end{array}$ & $\begin{array}{c}\text { Road } \\
\text { grade } \\
{[\text { degree] }}\end{array}$ & $\begin{array}{c}\text { Friction } \\
\text { coefficient } \\
{[-]}\end{array}$ & $\begin{array}{c}\text { Steady-state } \\
\text { off-tracking error* } \\
{[\mathrm{mm}]}\end{array}$ & $\begin{array}{c}\text { Parameter } \\
\text { changes }\end{array}$ \\
\hline 12 & B-double & 5 & 0 & 0.8 & 0 & Baselines \\
13 & A-triple & 5 & 0 & 0.8 & 0 & Road camber \\
\hline 14 & B-double & 0 & 0 & 0.8 & 530 & Adhesion \\
15 & A-triple & 0 & 0 & 0.8 & 910 & \& camber \\
\hline 16 & B-double & 0 & 0 & 0.1 & 1190 & 0.1 \\
17 & A-triple & 0 & 0 & 00 & & \\
\hline
\end{tabular}

Table 2: Path-following performance for LCVs: straight-line.

*calculated at the rear doors of the last trailer with respect to the front of the tractor

\begin{tabular}{|c|c|c|c|c|c|c|}
\hline Test & $\begin{array}{c}\text { Vehicle } \\
\text { type } \\
{[-]} \\
\end{array}$ & $\begin{array}{c}\text { Road } \\
\text { camber } \\
\text { [degree] }\end{array}$ & $\begin{array}{c}\text { Road } \\
\text { grade } \\
\text { [degree] }\end{array}$ & $\begin{array}{c}\text { Friction } \\
\text { coefficient } \\
{[-]} \\
\end{array}$ & $\begin{array}{c}\text { Steady-state } \\
\text { off-tracking error* } \\
{[\mathrm{mm}]}\end{array}$ & $\begin{array}{c}\text { Parameter } \\
\text { changes }\end{array}$ \\
\hline 18 & B-double & 0 & 0 & 0.8 & 1020 & Baselines \\
\hline 19 & A-triple & 0 & 0 & 0.8 & 1250 & \\
\hline 20 & B-double & 0 & 0 & 0.1 & 920 & Adhesion \\
\hline 21 & A-triple & 0 & 0 & 0.1 & N/A & \\
\hline 22 & B-double & 5 & 0 & 0.8 & 1330 & \\
\hline 23 & A-triple & 5 & 0 & 0.8 & 1200 & Road camber \\
\hline 24 & B-double & -5 & 0 & 0.8 & 720 & \\
\hline 25 & A-triple & -5 & 0 & 0.8 & 1200 & \\
\hline 26 & B-double & 0 & 5 & 0.8 & 22 & Road grade \\
\hline 27 & A-triple & 0 & 5 & 0.8 & N/A & \\
\hline 28 & B-double & -5 & 5 & 0.8 & 2 & Grade \& camber \\
\hline
\end{tabular}

Table 3: Path-following performance for LCVs: $450^{\circ}$ roundabouts.

*calculated at the rear doors of the last trailer with respect to the front of the tractor 


\section{Figures}

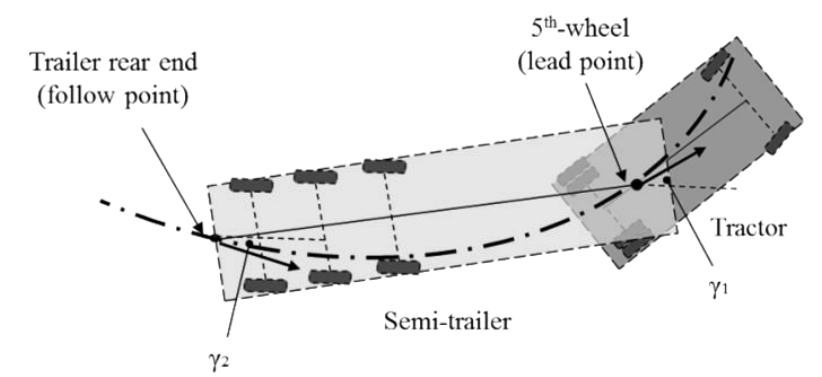

(a)

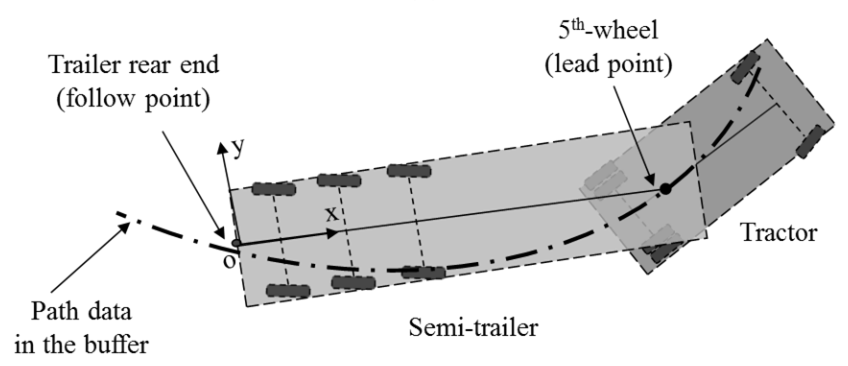

(b)

Figure 1: Path-following control strategies. (a) Jujnovich's heading angle based trailer steering system; (b) Cheng's tracking error based trailer steering system.

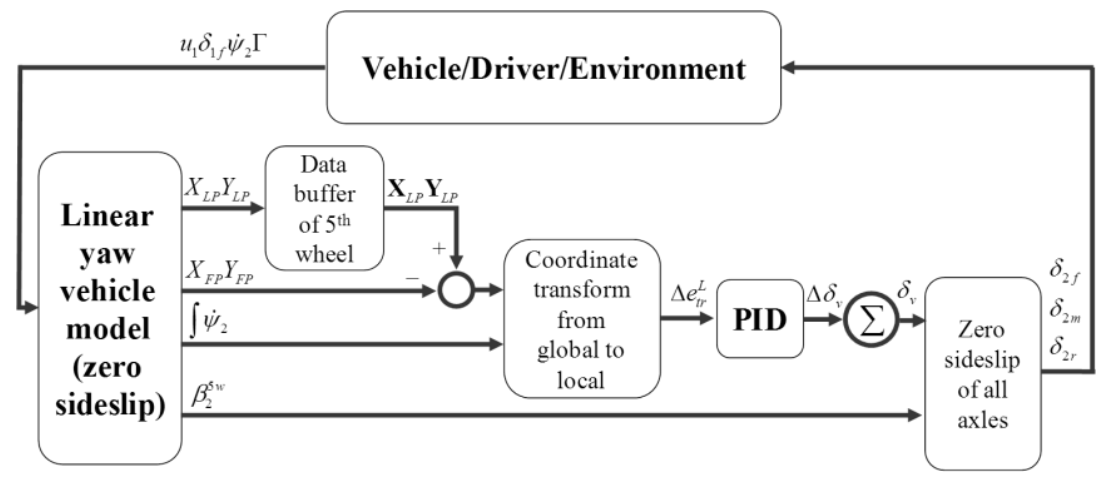

Figure 2: Schematics of path-following control from Cheng [3]. 
Tractor

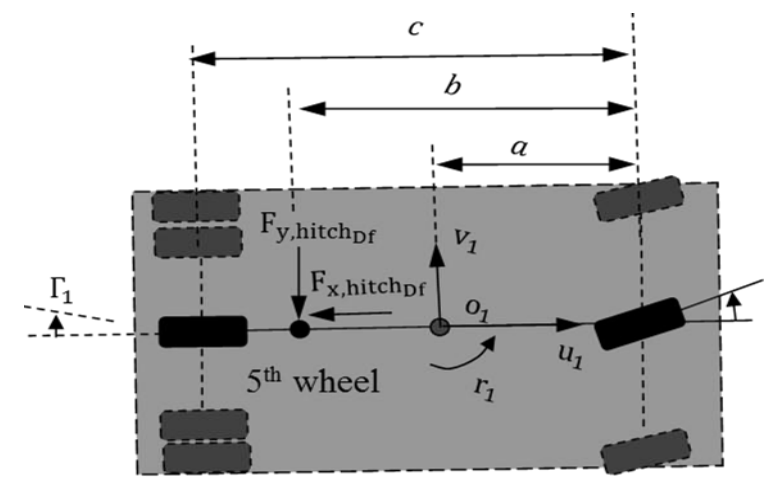

L

B-Trailer/

Dolly

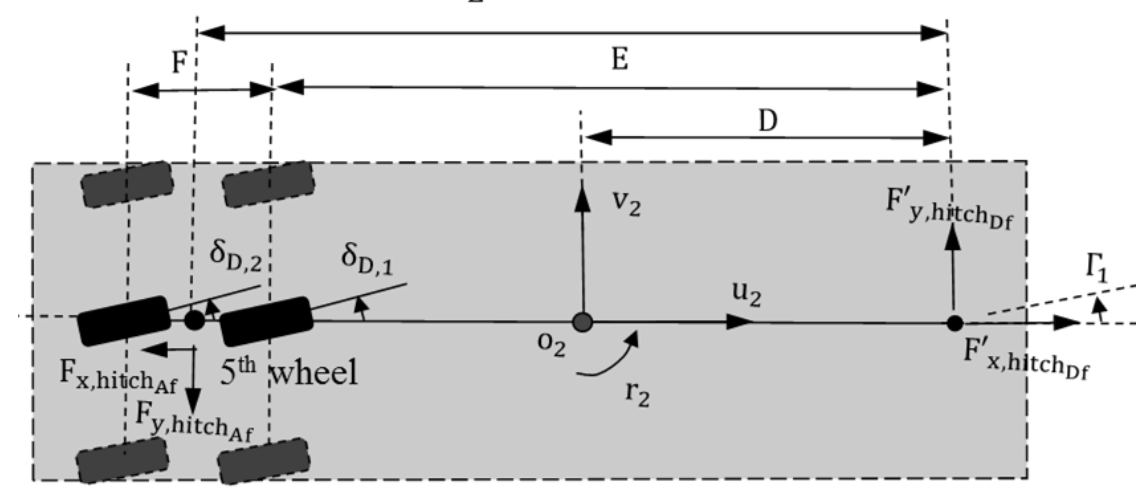

A-Trailer

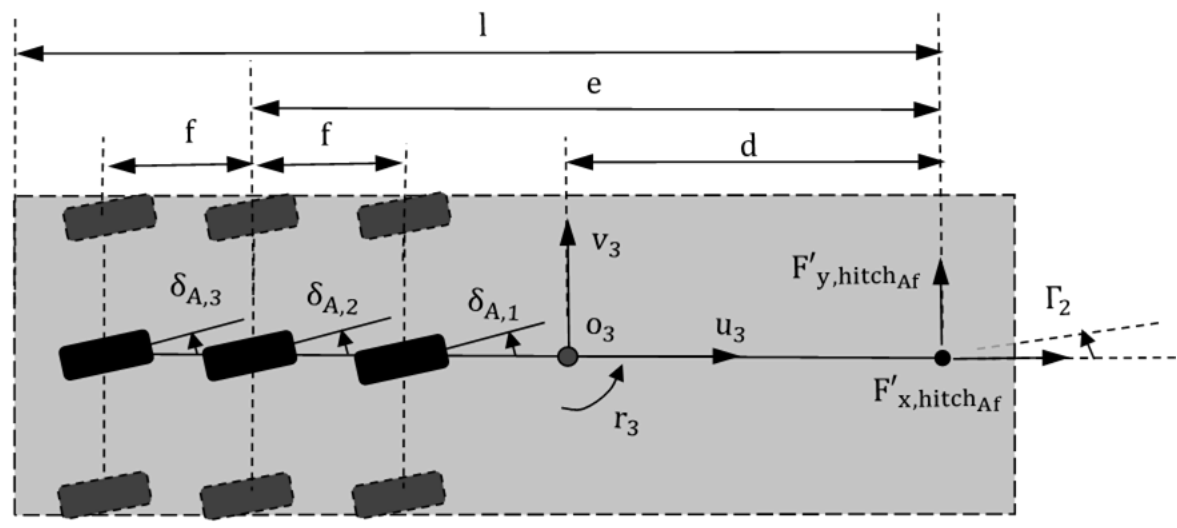

(a)

Figure 3: Definition of terms and dimensions for articulated vehicle models, showing the equivalent 'bicycle' model wheels on the longitudinal centre line. (a) $x-y$ plane 


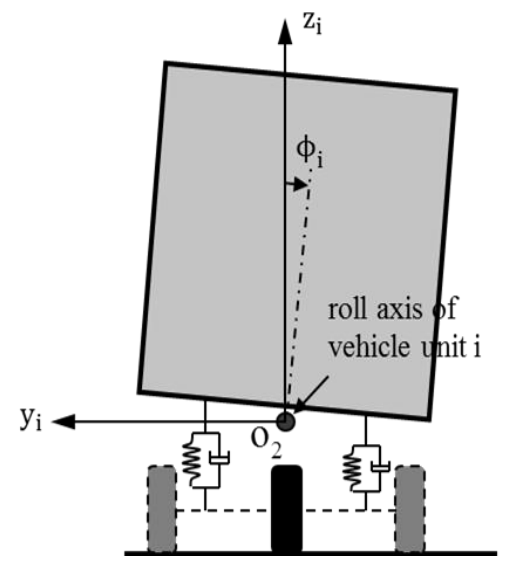

(b)

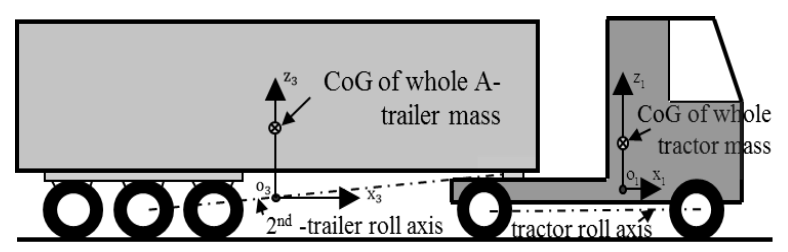

Tractor-semitrailer

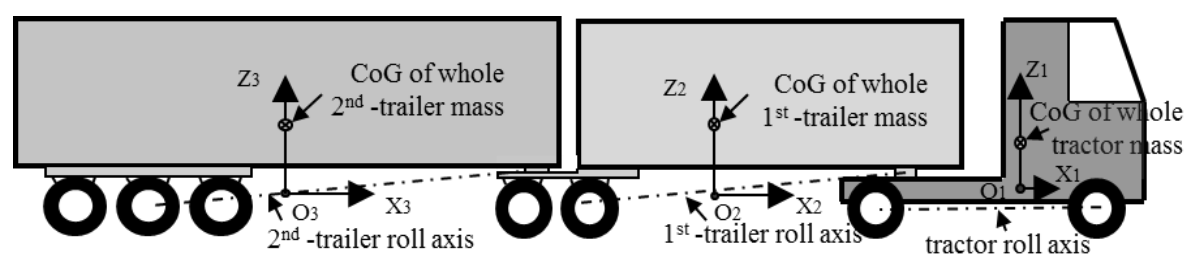

B-double

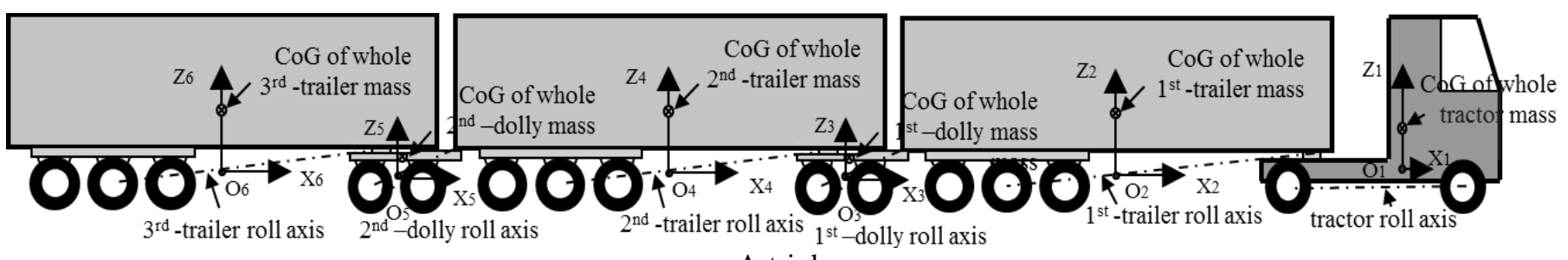

A-triple

(c)

Figure 3 (cont): Definition of terms and dimensions for articulated vehicle models. (b) y-z plane; (c) x-z plane.

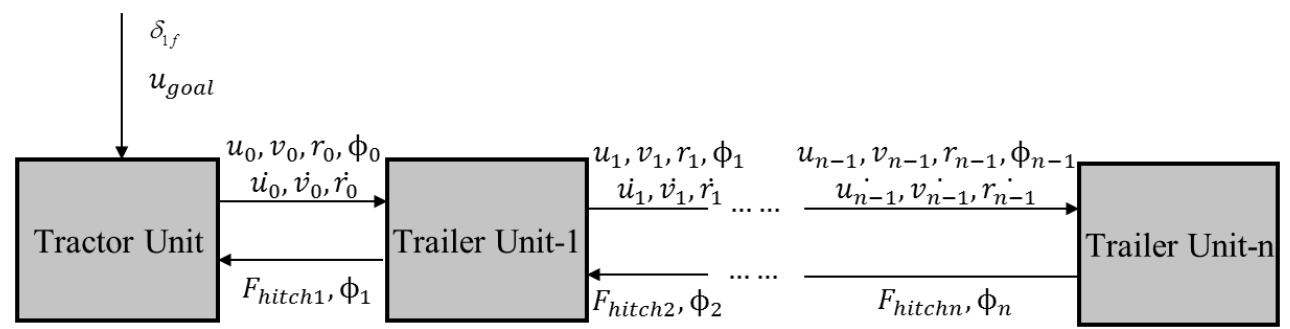

Figure 4: Block diagram of vehicle dynamics sub-model 


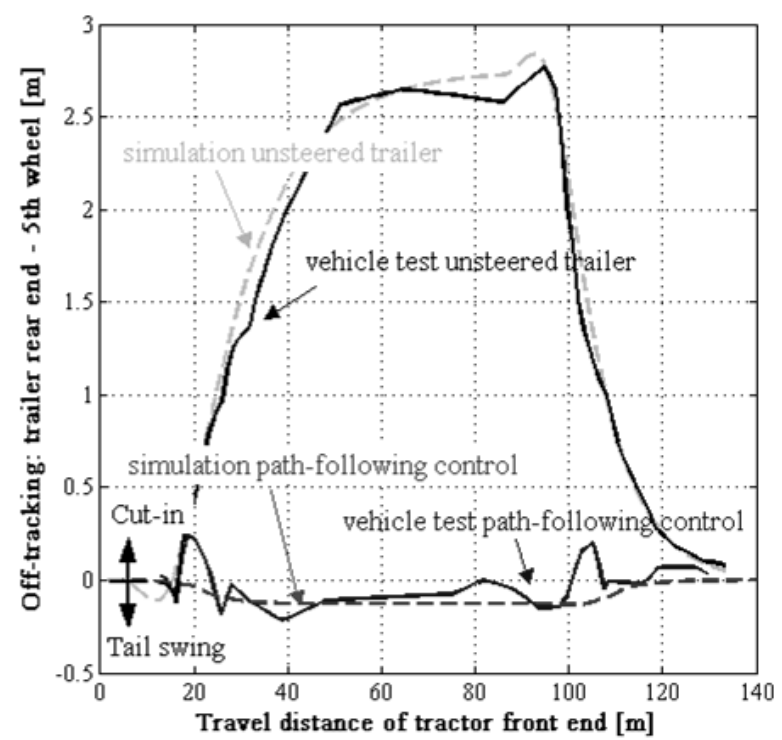

Figure 5: Simulated vs measured path-tracking error: trailer rear end relative to the 5th wheel for a $450^{\circ}$ roundabout on a flat road of high friction at $10 \mathrm{~km} / \mathrm{h}$ (model validation)

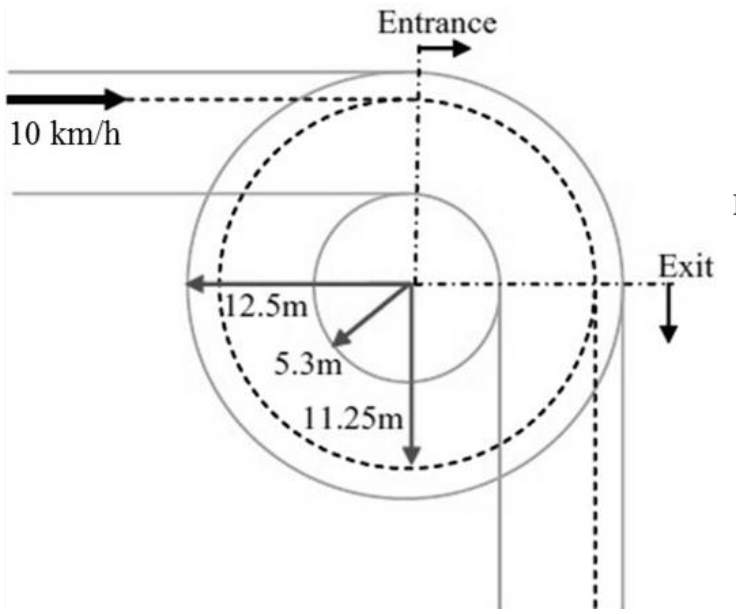

(a)

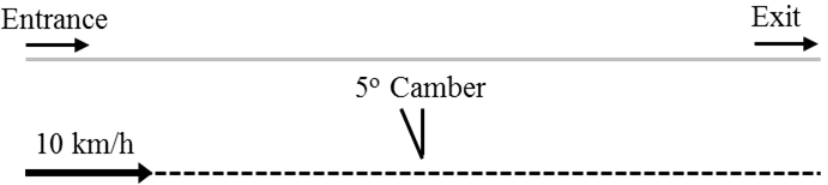

(b)

Figure 6: Illustration of two manoeuvres in parametric study: (a) $450^{\circ}$ Roundabout; (b) Cambered straight line.

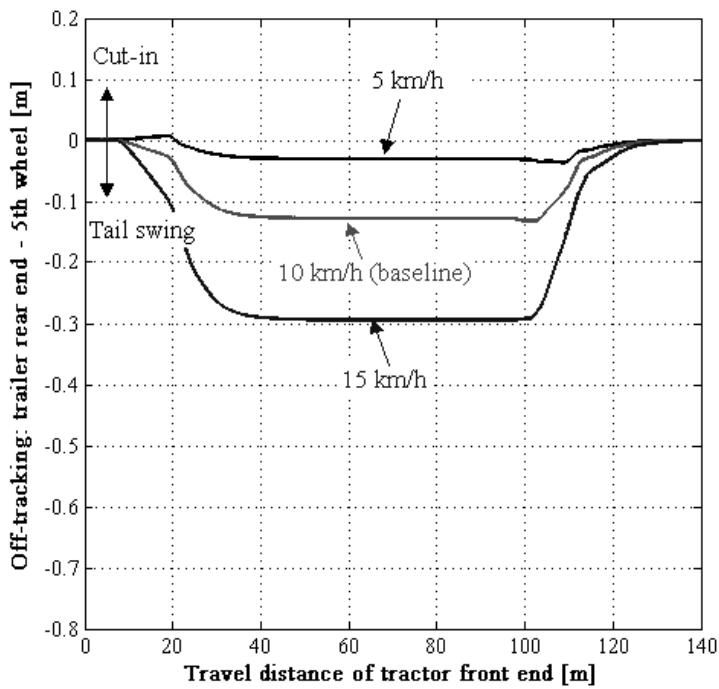

(a)

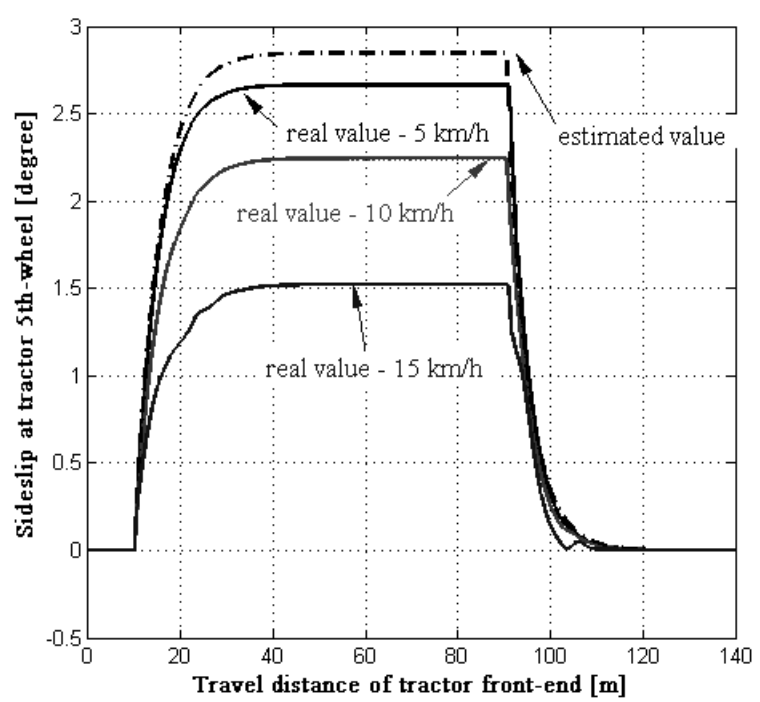

(b)

Figure 7: Effects of vehicle speed on path-following performance (Tests 1-3). (a) Path-tracking error: $5^{\text {th }}$ wheel to trailer rear end; (b) Sideslip at tractor $5^{\text {th }}$ wheel. 


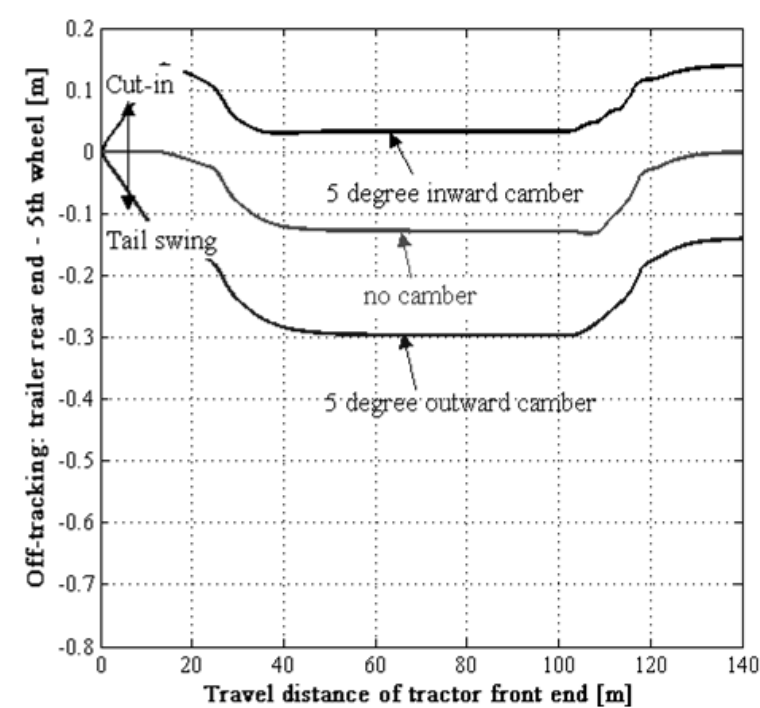

(a)

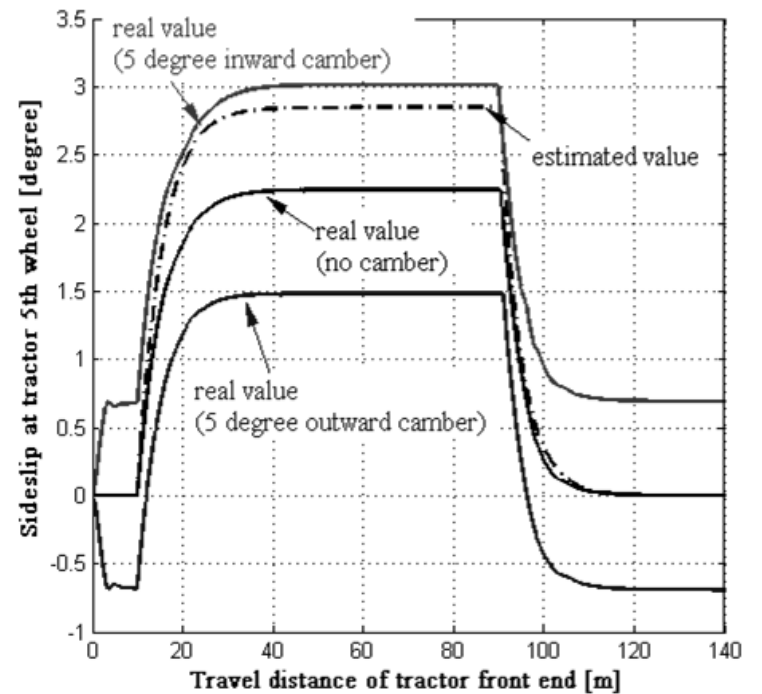

(b)

Figure 8: Effects of road camber on path-following performance (Tests 1,4 and 5). (a) Path-tracking error: $5^{\text {th }}$ wheel to trailer rear end; (b) Sideslip at tractor $5^{\text {th }}$ wheel.

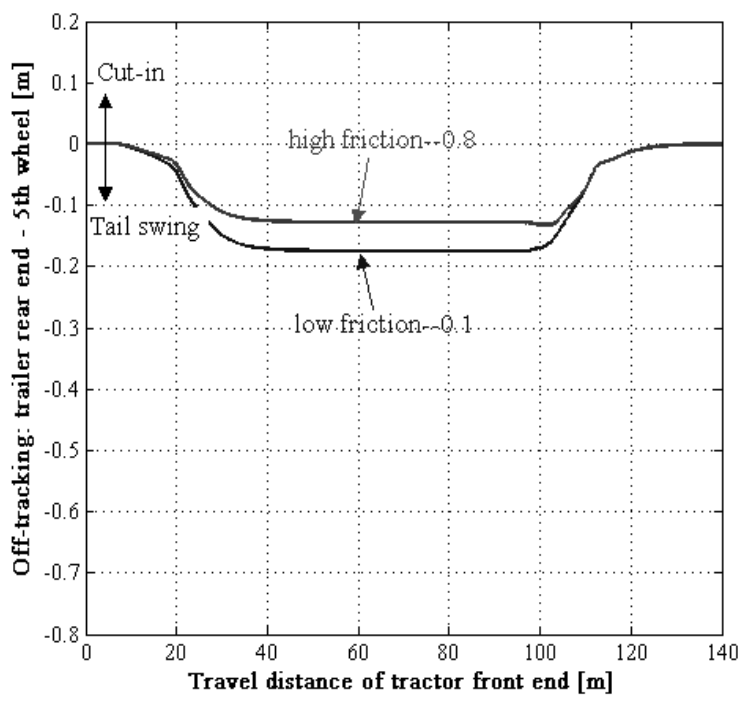

(a)

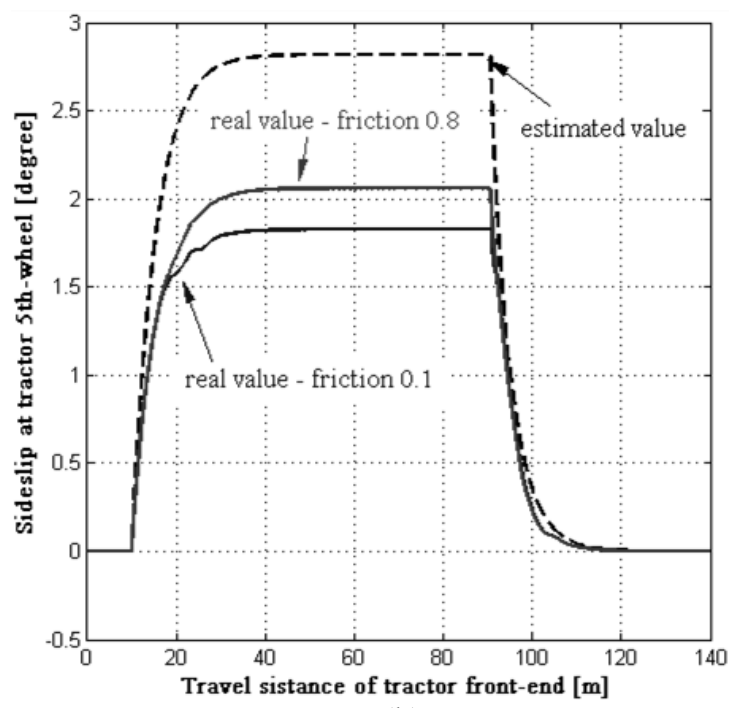

(b)

Figure 9: Effects of tyre-road adhesion on path-following performance (Tests 1 and 6). (a) Path-tracking error: $5^{\text {th }}$ wheel to trailer rear end; (b) Sideslip at tractor $5^{\text {th }}$ wheel. 


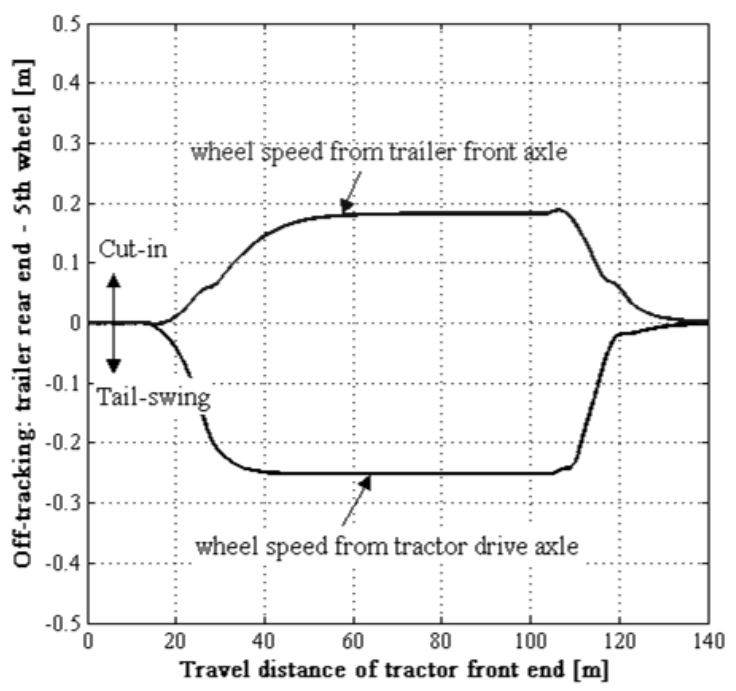

(a)

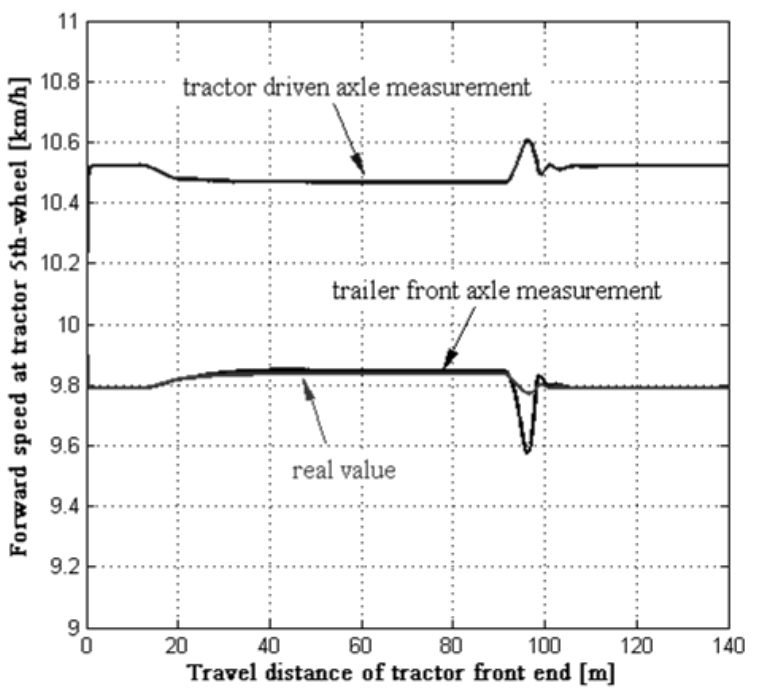

(b)

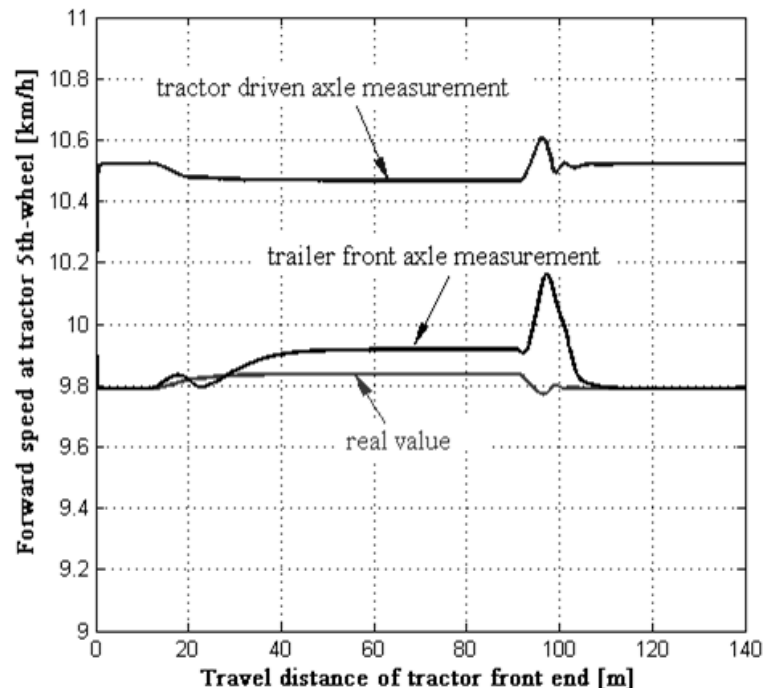

(c)

Figure 10: Effects of road grade on path-following performance (Tests 1, 7 and 8). (a) Path-tracking error: $5^{\text {th }}$ wheel to trailer rear end; (b) Path-tracking error: $5^{\text {th }}$ wheel to trailer rear end; (c) Sideslip at tractor $5^{\text {th }}$ wheel.

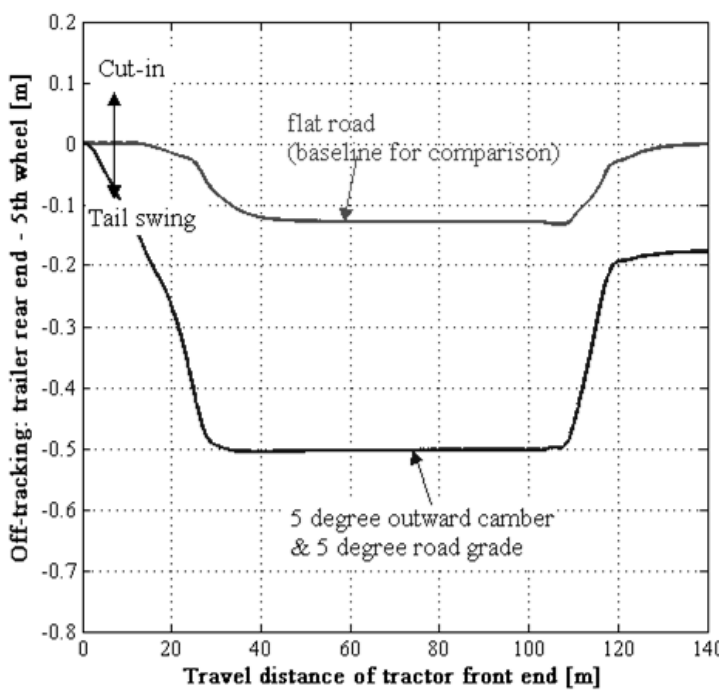

(a)

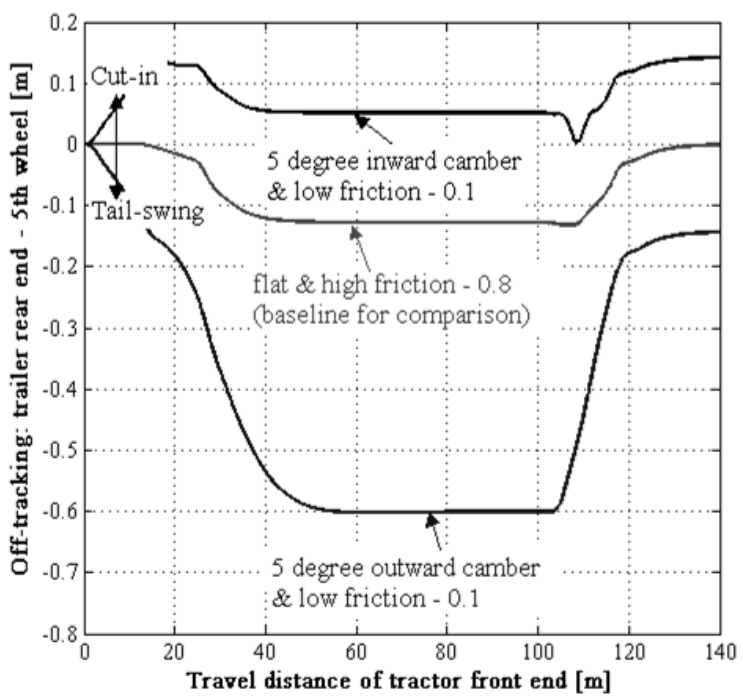

(b)

Figure 11: Effects of tyre-road adhesion on path-following performance (Tests 1, 9-11). (a) variation of road camber and grade (Test 9); (b) variation of road camber and adhesion (Tests 10-11). 


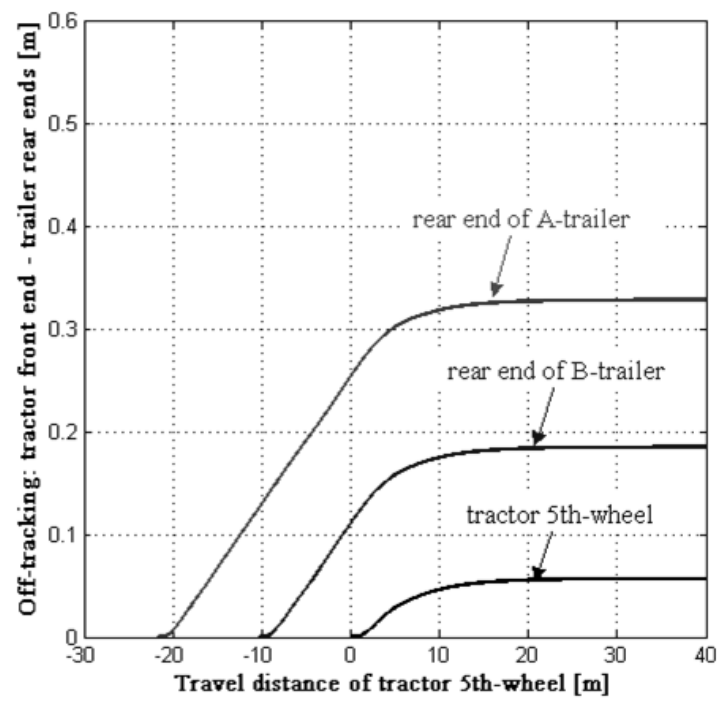

(a)

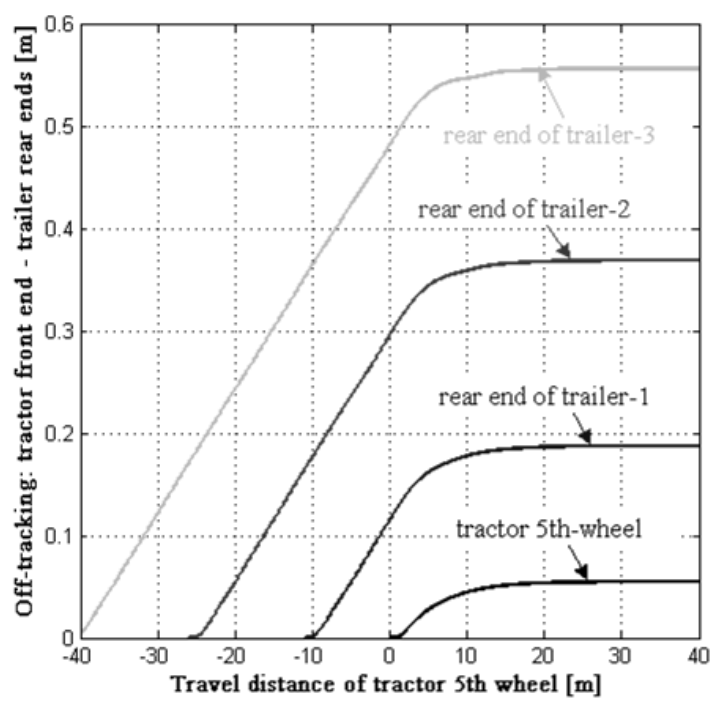

(b)

Figure 12: Path-tracking error: front end of tractor to rear ends of trailers (Tests 14-15). (a) B-double (test 14); (b) A-triple (test 15).

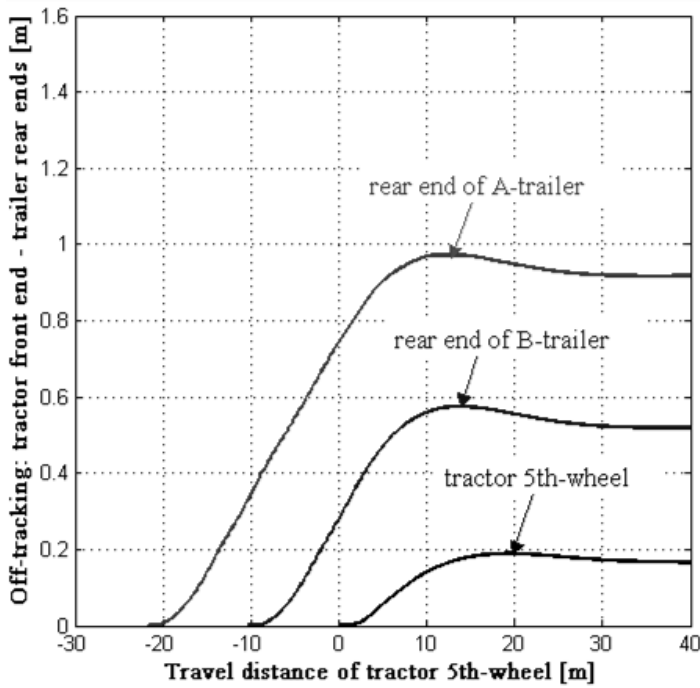

(a)

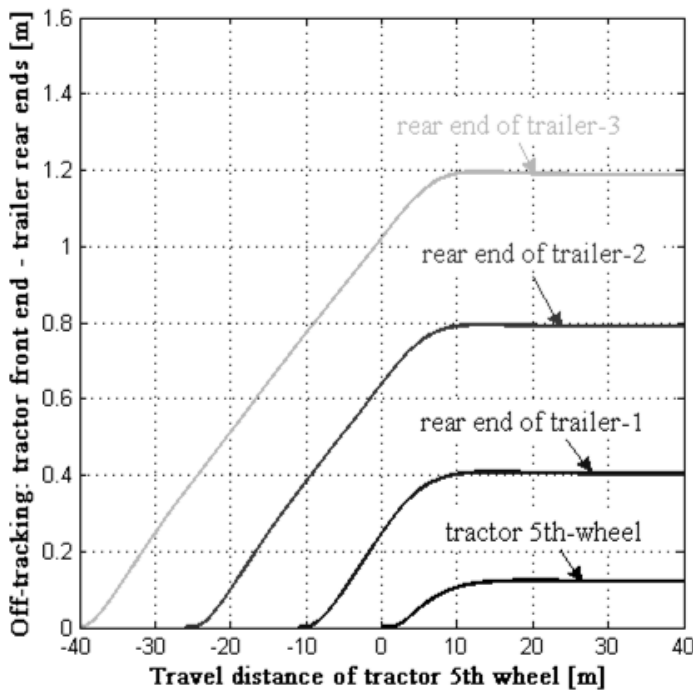

(b)

Figure 13: Path-tracking error: front end of tractor to rear ends of trailers (Tests 16-17). (a) B-double (test 16); (b) A-triple (test 17) 


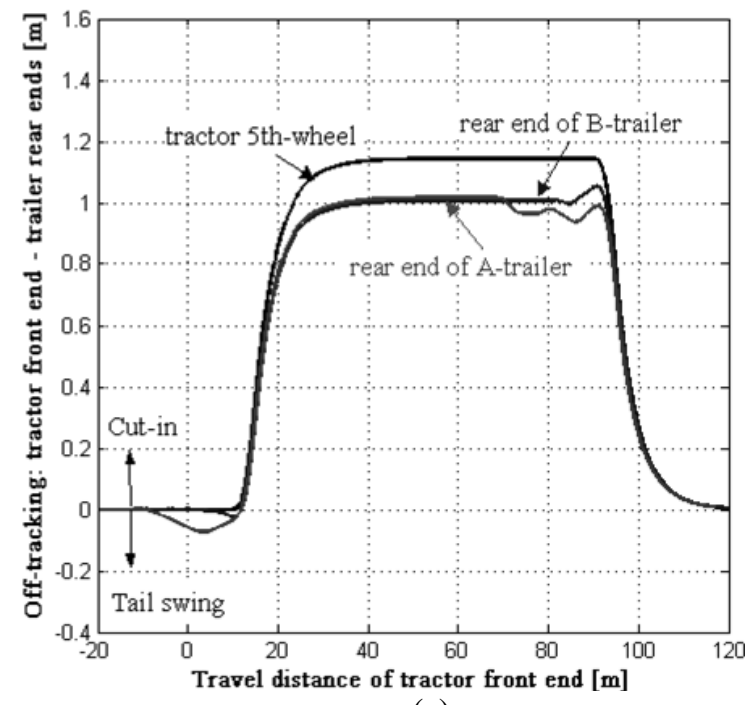

(a)

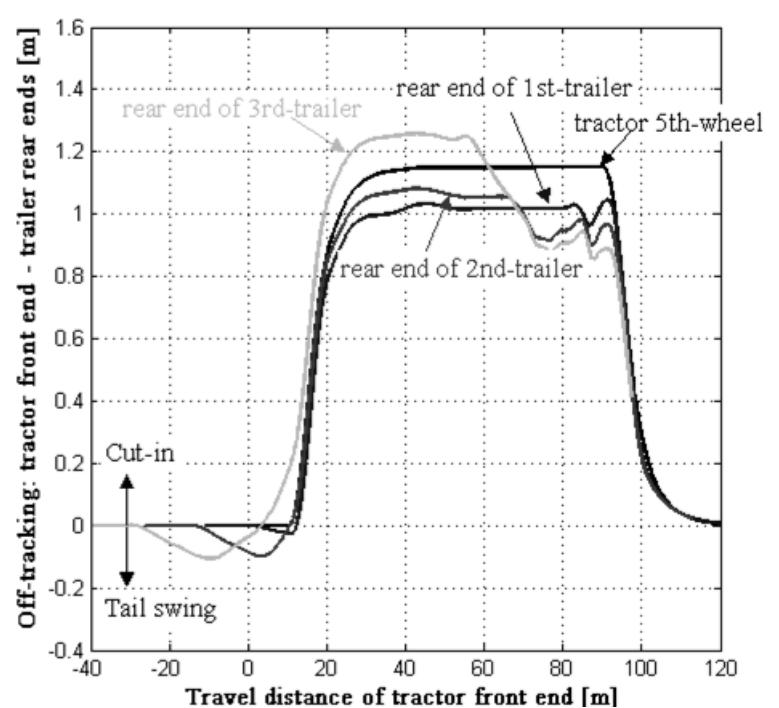

(b)

Figure 14: Path-tracking error: front end of tractor to rear ends of trailers (Tests 18-19). (a) B-double (test 18); (b) A-triple (test 19)

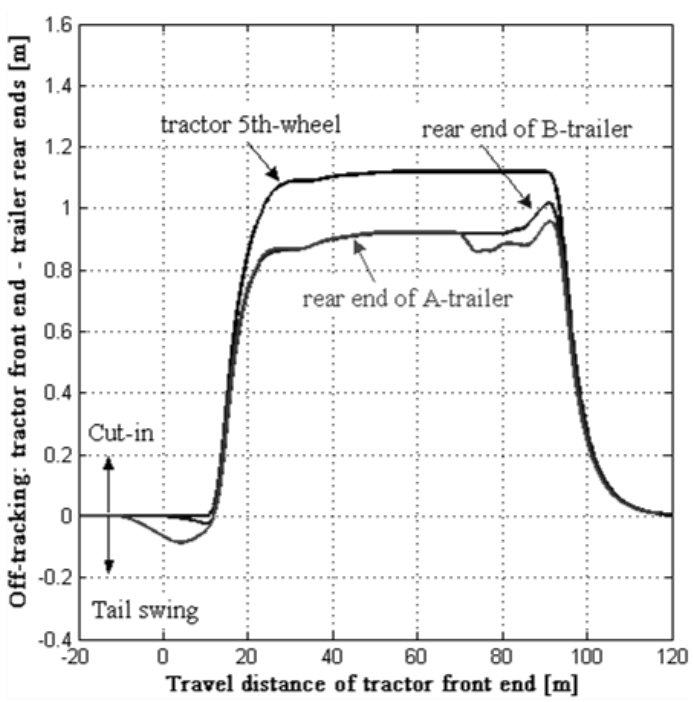

(a)

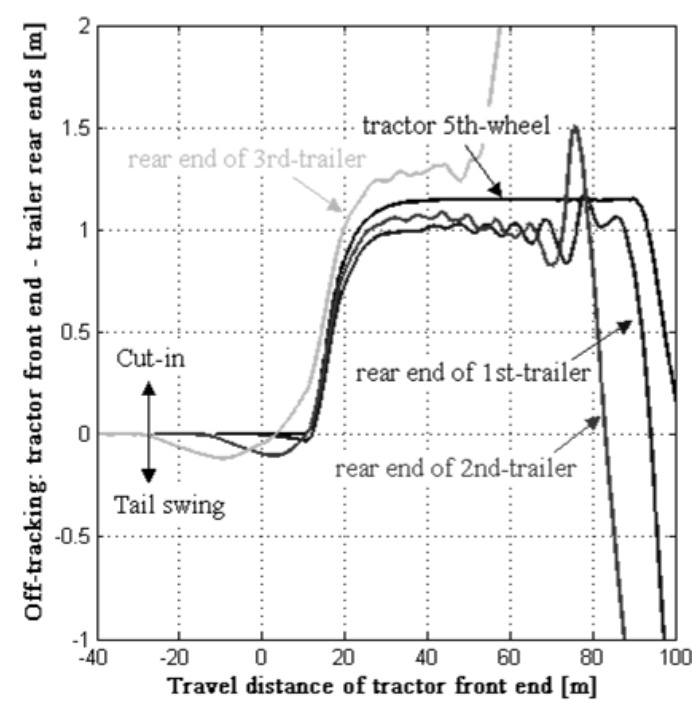

(b)

Figure 15: Path-tracking error: front end of tractor to rear ends of trailers (Tests 20-21). (a) B-double (test 20); (b) A-triple (test 21) 


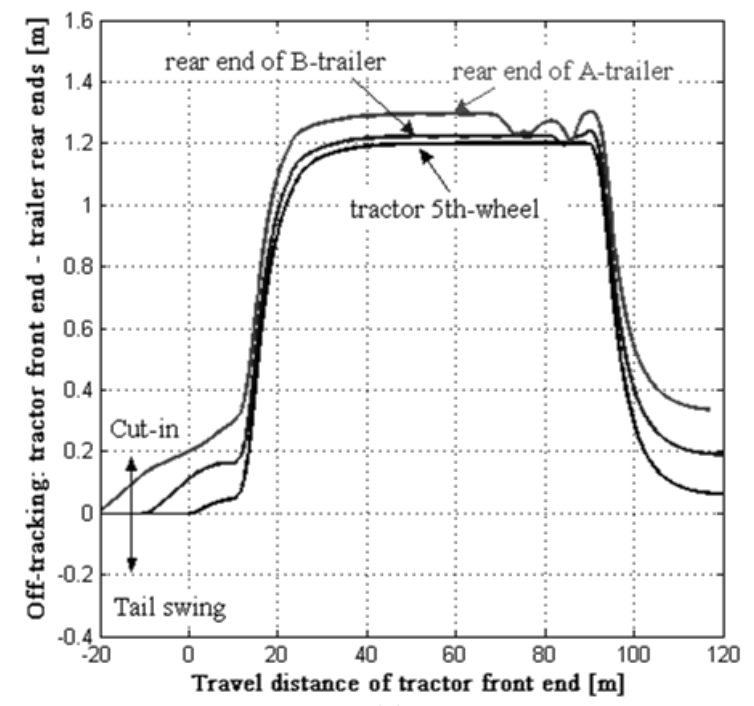

(a)

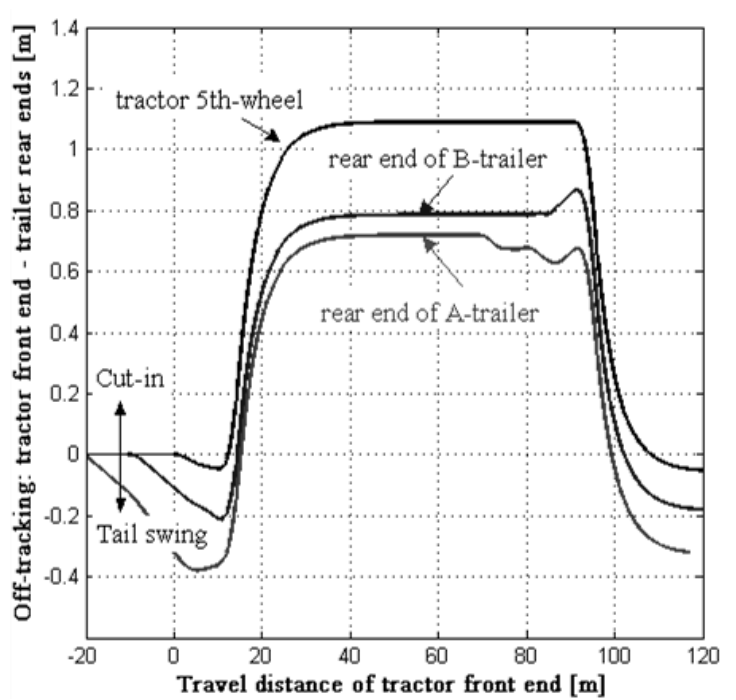

(c)

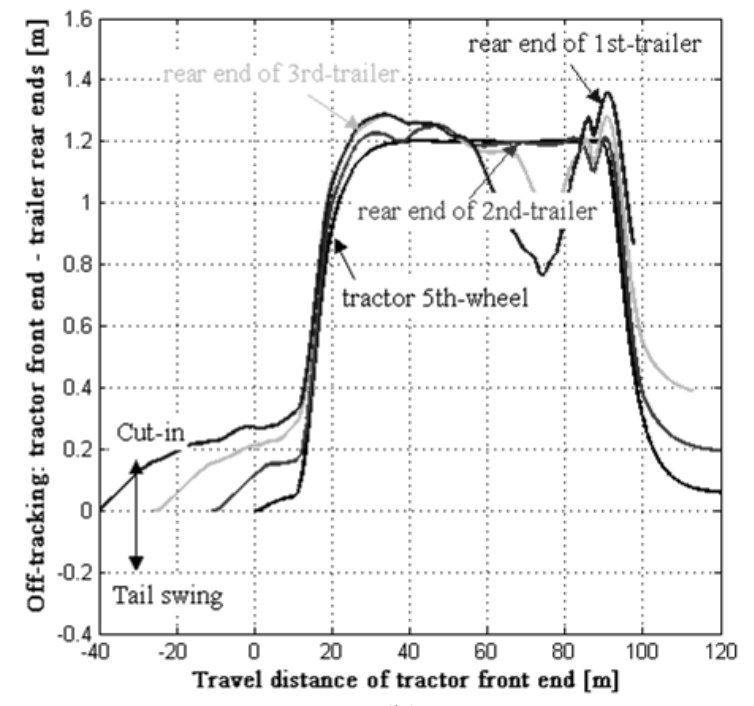

(b)

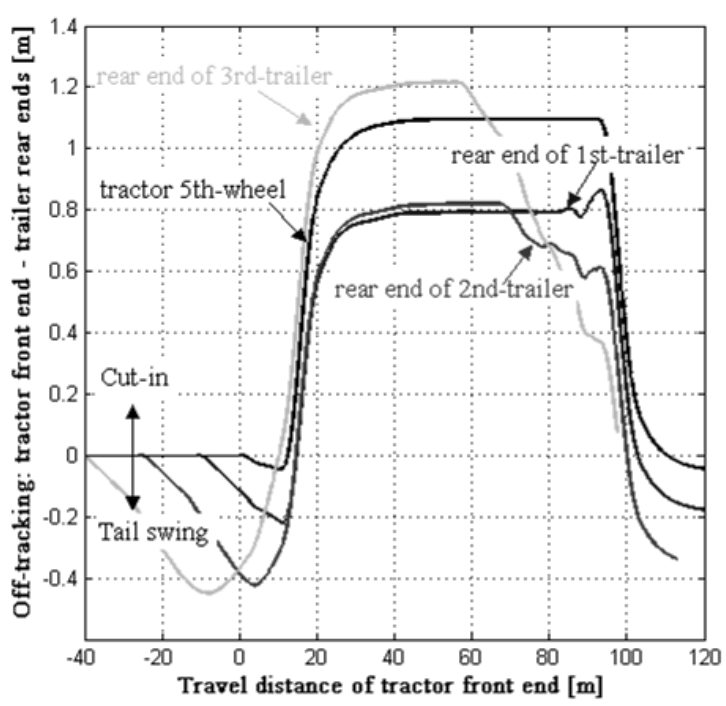

(d)

Figure 16: Path-tracking error: front end of tractor to rear ends of trailers (Tests 22-25). (a) B-double ( $5^{\circ}$ camber, test 22); (b) A-triple ( $5^{\circ}$ camber, test 23); (c) B-double $\left(-5^{\circ}\right.$ camber, test 24$)$; (d) A-triple $\left(-5^{\circ}\right.$ camber, test 25$)$. 


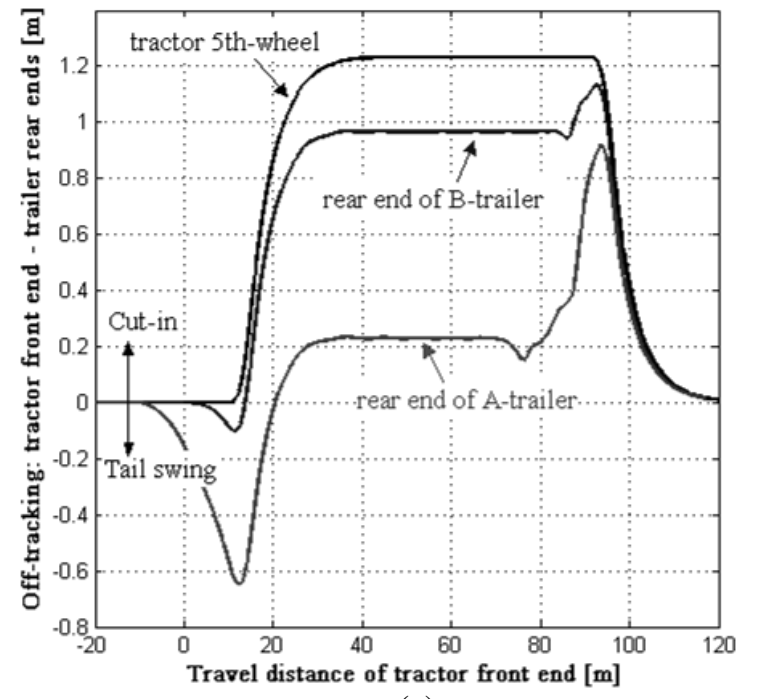

(a)

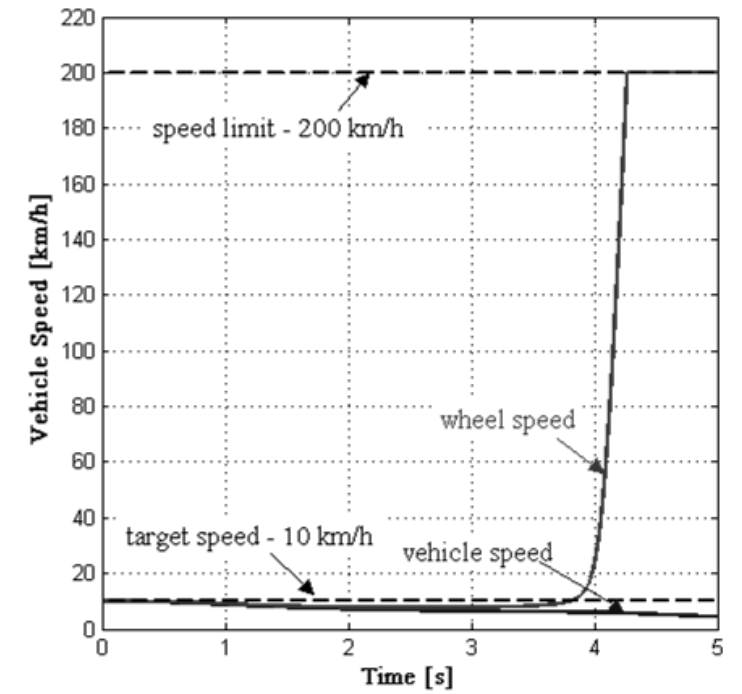

(b)

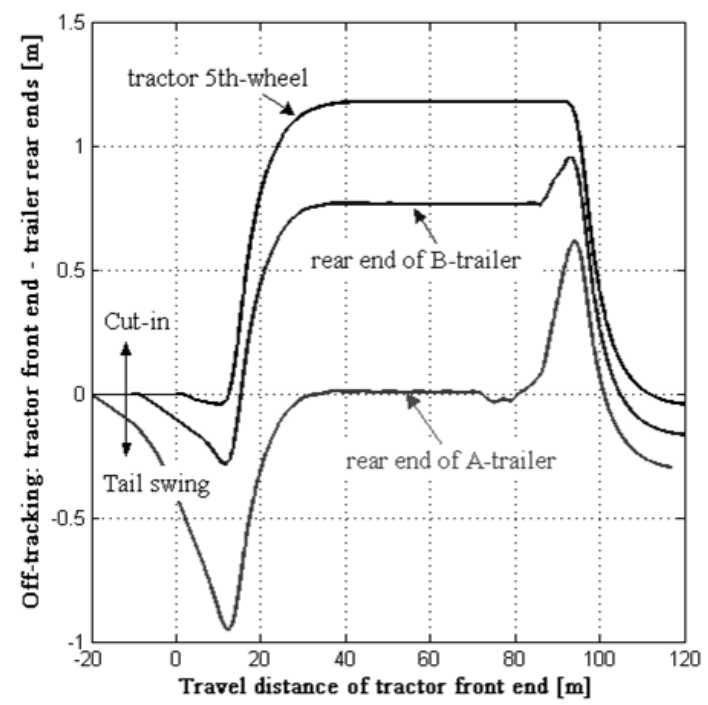

(c)

Figure 17: Path-tracking error: front end of tractor to rear ends of trailers (Tests 26-28). (a) B-double $\left(5^{\circ}\right.$ grade, test 26); (b) A-triple ( $5^{\circ}$ grade, test 27$)$; (c) B-double ( $5^{\circ}$ camber and grade, test 28 ).

\section{References}

1. Jujnovich, B.A., Active Steering of Articulated Vehicles, 2005, University of Cambridge: Cambridge, UK.

2. Woodrooffe, J., Economic Efficiency of Long Combination Transport Vehicles in Alberta, 2001,

Woodrooffe \& Associates: Ottawa, Canada.

3. Cheng, C., Enhancing Safety of Actively-Steered Articulated Vehicles, 2009, University of Cambridge: Cambridge, UK.

4. Jujnovich, B.A. and D. Cebon, Path-Following Steering Control for Articulated Vehicles. ASME Journal of Dynamic Systems Measurement and Control, 2013. Vol. 135(No. 3).

5. Roebuck, R.L., et al., Implementation of Trailer Steering Control on a Multi-Unit Articulated Vehicle at High Speeds. ASME Journal of Dynamic Systems, Measurement and Control, 2014. Vol. 136(No. 2).

6. Miao, Q., Vision - based Path - Following Control of Articulated Vehicles, in Department of Engineering 2015, University of Cambridge: Cambridge, UK.

7. ODHAMS, A.M.C., et al. Implementation of Active Steering on a Multiple Trailer Long Combination Vehicle. in Proceedings of the 10th International Symposium on Advanced Vehicle Control. 2010. Loughborough, UK.

8. Winkler, C.B. and P.S. Fancher. Directional Dynamics of Multi-Articulated Heavy Trucks Employing Controlled Steering of Dolly Wheels. in Proc. 10th IAVSD Symposium. 1987. Prague, CSSR. 